\title{
ORGANIZATIONAL CULTURE VECTOR IMPORTANT FOR THE PERFORMANCE OF A COMPANY
}

\author{
Elena-Izabela Popa $^{{ }^{*}}$, Amalia Furdui ${ }^{1}$, and Eduard-Victor Edelhauser ${ }^{1}$ \\ ${ }^{1}$ University of Petroșani, Universității Street, No. 20, Petroșani, România
}

\begin{abstract}
Organizational culture has become a fashionable subject in recent years, a topic that has been approached frequently in both academic and economic environments. Its importance is mainly reflected by the impact it has on the results of an organization. Thus, whether a public institution, a state-owned or a foundation society, we can definitely appreciate that a healthy organizational culture is a safe chance for success, it is one of the main factors that can determine the performance of that organization. In this context, the paper addresses a topic that has been little explored in the Romanian literature: to establish a possible link between the organizational culture and the performance of an organization. In order to achieve a first pragmatic approach to the research topic, we have conducted a case study on the assessment of organizational culture within a power generation company. This study evaluated the organizational culture in the company and analyzed whether the organizational culture influences its performance. The case study is not representative of Romania, but it is only a trend reflected by a company that produces electricity and which has posed the issue of assessing the organizational culture and its impact on its long-term performance. The research was conducted on a representative sample for management and executives. Through the research, the organizational culture was evaluated, its specificity was highlighted, and the organizational culture within the company was observed. It has been analyzed whether the organizational culture is understood by the employees and whether they fully adhere to it, but also the link between this concept and the company's performance. The management segment that refers to organizational culture is of great importance in the structure of a company as it can influence its results. Culture could be used to improve employees' actions within a company if it is managed correctly, creating a competitive advantage, thus differentiating companies from one another. Taking these issues into account, understanding and using the concept of organizational culture as a tool within a company has become impetuously necessary if a company targets a top position in the ranking of the domain in which it operates. It is obvious that understanding of culture is crucial to managerial and organizational action, not just a causal relationship between organizational culture and performance.
\end{abstract}

\footnotetext{
Corresponding author:izapopa1974@yahoo.com
} 


\section{Introduction}

Organizational culture is one of the important concepts that have been relatively recent and have influenced in a significant way the way of thinking and action of researchers, teachers and students, managers and entrepreneurs, and specialists from various organizations from all over the world.

Interest has increased exponentially as a result of pressures from within and outside organizations, pressure for better knowledge, and an increase in the competitiveness of organizations and their constituents in order to survive and develop under the new conditions.

The major reassessment of the role the human resource has in the evolution of the organization has favored the development of the concept of organizational culture.

Organizational culture is the social energy that causes people to act, and is considered the invisible "force" behind the easily observable and tangible things in an organization. We can compare the organizational culture of an organization with the personality of an individual, which meets a number of visible and less visible aspects, but which provides the vision, meaning, direction and energy necessary for evolution.

Organizational culture helps us understand the differences that occur in an organization between what is formally stated officially by the mangers and what is actually happening within the organization. The various rules, procedures, statements, statements or decisions are interpreted and, to a certain extent, even applied through organizational culture. Beyond formal elements that attempt to centralize a certain attitude and behavior for members of the organization, organizational culture, moreover, creates and develops certain behavioral patterns that may or may not be in line with official versions. Much of the elements that make up the organizational culture are often intangible, unwritten, but with a particularly powerful influence.

In order to have a strong company, senior management, managers on other hierarchical levels, and other employees need to know and take into account this complex "complex" patrimony of the organization, because through decisions and actions to direct the energy generated by organizational culture to the achievement of the company's goals set out in its strategies and policies. [1]

The paper is structured in four chapters, the first chapter presents general aspects, the second chapter presents the theoretical aspects related to the organizational culture, among which the concept, its definitions, features, characteristics, and modalities of manifestation. Chapter Three is intended exclusively for the case study, a study aimed at analyzing organizational culture in a company that produces electricity and has state-owned capital. In Chapter Four we presented the conclusions of the study.

The study has helped me from a theoretical point of view to deepen my knowledge of the organizational culture, which has a special significance in the performance of an organization, and the practical part of the work has contributed to a better understanding of the theoretical aspects.

\section{Organizational culture-concept and definitions}

The concept of organizational culture has its roots in social situations, anthropology, sociology, social psychology, and the behavior of the organization.

After the Second World War, the rise of Japan as one of the world's most powerful economic forces contributed substantially to the closer study of the culture-managementperformance relationship.

With almost no natural resource and overpopulation of nearly 126 million people, although it suffered major damage during the war, Japan managed to achieve the highest 
rate of economic growth, the lowest level of unemployment and create a climate of stimulating work for employees of organizations.

The American and Western European specialists have shown a special interest in explaining the Japanese "miracle", which has led to the consideration of culture, both macro and micro, as a determinant of the functionality and performance of the organization.

Since the 1970s, organizational research has begun to use cultural concepts to analyze organizations' behavior.

The phrase "organizational culture" was introduced in the literature in 1979 by Pettigrew in his work "On studying organizational culture". Pettigrew conducted a study on the evolution of an English school under the influence of events that were perceived by members of the organization as critical events from its establishment in 1934 to 1975 when the author collected the latest data. [2]

There has been a significant increase in the popularity of organizational culture since the 1980s, relevant to this being the works of Terrence Deal and Allan Kennedy (1982) "Corporate Culture: The Rites and Rituals of Corporate Life", "In Search of Excellence: Lessons form America's Best Run Companies "by Thomas Peters and Richard Waterman (1982), and Geert Hofstede's (1980)" Culture's Consequences ", their appearance triggering the explosion of research into the concept of organizational culture.

In the early 1990s, there was a reduction in the focus of the idea of the undeniable importance of organizational culture and people as individuals in organizations, also encouraged by the decline in the prestige of American companies and the profits made by Japanese until that time.

After 1990, the emergence of multinational companies' investments in the countries of Eastern Europe made the concept of organizational culture known in this area of the world. Specialists have described culture as a basic component of a society. Many see culture as one of the critical aspects of organizational adaptation and describe culture as a "system that transmits behavioral patterns to connect human communities to the surrounding environment."

The emphasis placed on the human factor as the main resource of the organization is reflected by the emergence and development of disciplines such as "Organizational Behavior", "Human Resource Management", with a wide impact in economic practice as well.

Thus, a number of social factors, such as morality, ethics, attachment, satisfaction, involvement, etc. at work, are increasingly being considered.

For example, psychological participation is considered to be the level of influence that an individual feels he has on the decision-making process.

This explains why mixed teams of psychologists, sociologists, economists, and technicians are being set up in competitive organizations to analyze specific issues such as the quality of life in the organization, the satisfaction of the job, the productivity of work, etc.

The term "culture" derives from anthropology. It has been used to represent, in a very broad sense, the physical and spiritual elements that a certain human community has transmitted from one generation to the next.

In the American Heritage Dictionary, culture is defined as "the totality of beliefs, values, behaviors, institutions, and other results of human thought and labor that are transmitted socially within a community."

"Webster's New Collegiate Dictionary" defines organizational culture as "a model of integrating human behavior that includes ways of thinking, language, action, and artifacts, and which depends on human capacity in learning and transmitting knowledge to generations next". 
Although this concept has been debated and publicized, in recent years there has not yet been a universally recognized definition of organizational culture.

Ouchi defines organizational culture as "a set of symbols, ceremonies, and myths that communicate the basic beliefs and values of the organization of its members." [3]

Peters and Waterman regard organizational culture as "a coherent and dominant set of shared values, transmitted by symbolic means such as stories, myths, legends, slogans, anecdotes, stories." [4]

Andre Laurent believes that "an organization's culture reflects the presumptions about customers, employees, mission, products, presumptions that have worked well in the past and that have been translated into attitudes, behaviors, expectations, what is legitimate, thinking and action". [5]

Ovidiu Nicolescu believes that "organizational culture resides in all the values, beliefs, aspirations, expectations and behaviors outlined in each organization, which predominates within it and which directly and indirectly condition its functionality and performance." [6]

Edgar Schein sees organizational culture as "a model of basic presumptions learned, discovered, or developed by a particular group, a certain community, in learning how to successfully solve the problems of external adaptation and internal integration that has worked well enough for a certain period of time to be validated and to be passed on to new members as the right way to perceive, think, and feel about those issues." [7]

The most prominent of organizational culture research workers, Geert Hofstede, defines culture as "a collective mental programming that differentiates members of a group or a particular social category from members of other groups or social categories". [8]

In our view, organizational culture represents the totality of values, symbols, rituals, ceremonies, myths, attitudes and behaviors that are dominant in an organization, are passed on to the next generation as the normal way of thinking, feeling and acting and having a determining influence on its results and evolution.

Although organizational culture has received many definitions, it is noted that there are a number of common features:

- All definitions take into account a set of meanings and values belonging to individuals in the organization;

- Elements of organizational culture need a relatively long time to form;

- The meanings and values that form the basis of organizational culture are a synthesis of individual and national ones, appearing at the intersection of the two major categories of elements;

- Values, beliefs are reflected in symbols, attitudes, behaviors and different structures, formal or informal;

- Organizational culture is a reference framework for members of the organization;

- The manifestations of the organizational culture influence the organization's performance and performance.

Organizational culture can be measured in Gh. Gh. Ionescu's sense by the following 10 characteristics:

- The individual initiative, the degree of responsibility, freedom and independence enjoyed by individuals;

- The risk tolerance, the degree to which employees are encouraged to be innovative and take the risk.

- Direction, the degree to which the organization creates clear objectives and the expected, expected performance.

- Integration, the degree to which organizations in organizations are encouraged to operate, and act in a coordinated manner.

- Management support, the degree to which managers provide clear communication, assistance and support to their subordinates. 
- Control of the number of rules and regulations and the amount of direct supervision that is used to monitor and control the employee's behavior.

- Identity, the degree to which members identify with the organization as a whole more than their first group of work or the field of professional experience.

- The reward system, the degree to which reward allocations are based on employee performance criteria, in contrast to seniority, aphorism, etc.

- Conflict tolerance, the degree to which employees are encouraged to resolve conflicts and to be open to criticism.

- Models of communication, the extent to which organizational communications are restricted to the authority of the formal hierarchy. [9, 10]

\subsection{The ways of manifesting the organizational culture}

Organizational culture is made up of a series of elements that can be more or less visible, depending on how profoundly we manage to penetrate into its layers. The difficulty of perceiving an organization's culture stems both from the diversity of its forms of manifestation, its visibility, and from the fact that it comprises elements that manifest at the conscious level but also at the subconscious level at a rational but also sentimental level, emotional.

The ways in which organizational culture manifests itself takes on a great variety of forms as we have synthesized in the following figure [11]:

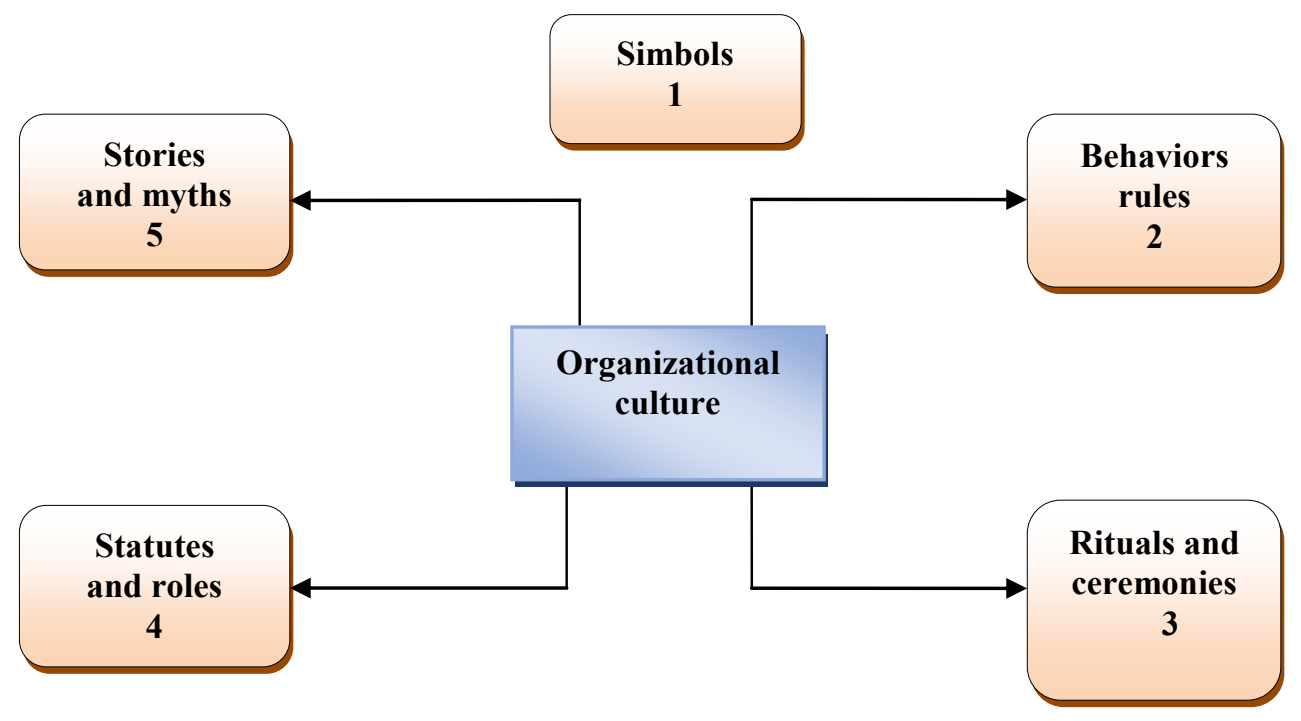

Fig. 1. Manners of organizational culture

Symbols are major components of organizational culture that offer meaning or common meanings to its members on organizational elements of group interest, enabling them to communicate and to harmonize. Cultural symbols transmit meaning that reveals the philosophy and values, ideals, beliefs or expectations shared by employees of the organization.

Behavioral rules are attitudes and behaviors expected to be displayed by employees within and outside the organization, as well as rewards / sanctions triggered by compliance/violation.

Rituals and ceremonies are certain collective patterns of behavior, especially in situations of predominantly formal character. 
Status is the prestige and position an employee has within the organization, as perceived by its members. [12]

Role is the pragmatic expression of the status. fiction.

Organizational history is a story based on true facts, but it also includes elements of

Myth is a complex that attempts to reflect a system of collective beliefs about the operating mechanisms of the surrounding world and the elements needed to enjoy success.

\section{Case study evaluation and analysis organizational culture in a electric power generation company}

Starting from the premise that an organization's performance is related to the quality of organizational culture, there is immediately a practical interest in assessing organizational culture. This assessment can be used for performance predictions as well as a starting point in a cultural modeling process that is supportive of strategy and better performance. [13]

Given the fact that the shared values of the individuals that make up an organization are believed to be the ones that induce organizational culture, subjective beliefs, unconscious traits, attitudes, expectations, and other observable phenomena related to heroes, rites, rituals and behavioral norms.

The purpose of this study is to make an assessment of organizational culture in a power generation company and to analyze whether organizational culture influences its performance.

In this paper, a case study will be carried out, which is not representative of Romania, but it is only a trend reflected by an electricity generation company, which raised the question of the evaluation of the organizational culture and its impact on its performance on long term.

The sample on which research was conducted inside the company is representative of management and executives. Through the research carried out, the organizational culture was assessed, the specificity of the culture within the company was observed, the organizational culture within the company was observed.

It has been analyzed whether the organizational culture is understood by the employees and whether they fully adhere to it, but also the link between this concept and the company's performance.

\subsection{Methodology of research}

Most techniques to assess the invisible level of organizational culture are based on questionnaires that measure a number of values considered by the creators of that technique as being associated with them.

The research method used was the survey based on a questionnaire. The questionnaire helped us determine organizational culture and evaluate it in terms of employee behaviors and how they perceive whether they fit with their organization and whether their expectations are met. 2019.

The questionnaire was applied to the company from December 5, 2018 to January 25,

To avoid the halo effect (employee tendency to respond similarly to multiple questions), a lean presentation of the questionnaire was chosen without delimiting by title the category or dimensions of the question.

The questionnaire used consists of 30 open, closed questions and even multiple answers. 
At the beginning it contains a short presentation of the subject of the questionnaire and then it is structured in two parts.

Part I of the generic questionnaire Identification data consists of a set of nine (nine) general questions in order to ease the entry into the subject.

Part II of the questionnaire, generically named Enterprise Valuation Data, contains a set of 21 questions introduced to determine what the values, norms, ethical principles of the organization and the extent to which employees adhere to values, goals, company policies.

The choice of scales for questions of this type (with scale) was made according to the studied variable, so as to avoid generating errors of appreciation (the tendency to give neutral or contradictory answers). The types of scales frequently used in the questionnaire are nominal scales, namely the yes-no-yes dichotomies, with neutral variation and a possible answer from a given list.

In the questionnaire we used also questions with an orderly scale with the hierarchy of preferences (most importantly, the least important), Likert (from total agreement to total disagreement), questions with scales with differentiation by importance (very much, not at all).

The criteria used for the applied research method were the accuracy of the results, the cost, the timing, the nature of the reference population, the volume of the sample, the available information.

The advantages that support the efficiency of the chosen method are: to facilitate the extraction of employees subject to the study, the possibility of rigorous control of the data collection process, a low cost and time of sample determination.

In order to ensure the confidentiality of the information on the respondents in order to increase the accuracy of the data obtained, their names were not specified, but only the position within the company, the gender and age of the respondent, plus the seniority in the company.

\subsection{Population and sample observed}

The population surveyed is made up of 50 employees. She is between 35 and 55 years of age, and from the gender perspective, the respondents are both women and men.

The questionnaire was distributed, through direct contact, to company employees in the personal driving and execution categories.

\subsection{Analysis and interpretation}

The data was collected, processed, analyzed and interpreted between January 26 and February 15, 2019.

All 50 questionnaires were correctly completed, and these were the subject of statistical analysis.

For data processing the Statistical Package for Social Sciences (SPSS) was used, one of the most used in statistical analysis of data. Computer software has been favored both because of availability and because it offers greater flexibility if the information to be obtained is predominantly of a qualitative nature, which has made it easier to record and analyze data.

It is not excluded that the results of this research contain possible errors caused by lack of experience in the field. 


\subsection{Research results}

Centralized data show that the company is geared to respecting ethical principles, values, promoting a customer-oriented attitude.

The company's mission is to produce efficient, clean and safe electricity.

The company's motto is Excellence through quality.

Behavioral rules: immediate execution of the orders of bosses, respect for discipline and order, ethical behavior and integrity, assuming responsibility and consequences for the deeds committed, teamwork are respected by employees.

Sources of information about the company's values are represented by: official site, internal communication network, intranet, regular meetings and training with employees, company regulations.

From the data analyzed, the company has a preference for oral communication, although written communication is governed by procedures, instructions and regulations of the company.

There is also, a desire to avoid conflicts in the company by reaching a compromise.

Employees adhere to the company's goals and policies, showing loyalty to it. Sources of information about company values are: internal regulation, ethical code, organization and operation regulations, system procedures, administrative and operational procedures, regular meetings and training with employees.

Following analysis and evaluation, the organizational culture of the company falls into: - Strong or positive culture, after contribution to performance, characterized by the homogeneity of values and perspectives that provide positive motivation;

- Process culture, according to the level of risk accepted and the speed of obtaining the feedback, being a rigid culture, based on strict rules and procedures; employees are disciplined, orderly, punctual and thorough;

- Hierarchical culture, according to the type of transaction by which the individual is linked to the company, because it is based on the observance of procedures and rules in a climate of stability and control; the authority is in the rules, and the power is exercised by specialists; decisions are based on detailed analyzes, and leaders tend to be conservative and cautious;

- Role culture (temple type), according to the configuration of the organization, because it is a large society, with bureaucratic mechanisms that lead to the emergence of subcultures in specialized departments, which form the columns on which the temple rests; the values and perspectives given by the roof of the temple are clear, expressed in writing, with the obvious tendency towards stiffening, discipline, compliance with codes, instructions, procedures, company regulations, employees are offered the possibility of a professional specialization;

- Eiffel Tower culture, depending on the characteristics of the organizations and the differences between the national cultures, because the relations between the employees are regulated in advance by imposed interactions; authority is attributed to the most important roles, people are distant but very strong;

- Collectivist culture, because it fosters interdependence, loyalty to the family or clan;

- Feminine culture, because it accepts different roles in genders, emphasizes gender equality;

- Strong avoidance, in terms of avoiding uncertainty (risk assumption, the extent to which employees feel uncomfortable in unsafe and ambiguous situations), because the rules, regulations, hard work, compliance, safety are emphasized;

- Culture with a long-term orientation, because it emphasizes perseverance, perseverance, thought and attention to position differences; 
- The short distance from power, because inequality is minimized, superiors are accessible power differences are not given great importance.

The result of the research shows that the company has a client-oriented attitude, respects and promotes values such as: professional excellence, team spirit, solidarity, valorization of synergies, ethics, integrity and loyalty, fairness and respect, business ethics business (internal and external) to colleagues, customers, suppliers respect and responsibility towards the community and the environment.

There are no differences between the values promoted within the company and those in which the employees find themselves. $95 \%$ of employees in the investigated sample are identified with organization values and adhere to company objectives and policies.

Therefore, it can be concluded that the assumptions of this research on the organizational culture of the company are valid and that moral values have an impact on the performance of the company and its employees.

\section{Conclusions}

Any organization can be seen as a social structure, made up of a group of people who act together to achieve the goals of the organization. The success of an organization is conditioned by the extent to which the staff acts in a united way to achieve its goals.

Organizational culture is a combination of conscious and unconscious, rational and irrational, group and individual elements that influence each other and have a major impact on the functionality and performance of society.

Peters and Waterman highlight in the work "The Price of Excellence" the secret of the best performing organizations and the features that must characterize excellence in their work. The authors illustrate the correlation between organizational culture and the organizational and organizational characteristics of organizations that have achieved appreciable performance, and consider organizational culture to be "the result of the effort of staff managers in the spirit of excellence. [14]

Quality oriented organizational culture is a guarantee of continued survival and development for any organization, regardless of whether it operates in a highly competitive market or in an unfavorable economic, social or political environment. This is because organizational culture, through its components, dictates certain behavioral norms of employees, guides how employees perceive and represent their reality, how to respond to environmental changes.

Performance will not be stimulated if attitudes, behaviors and methods used in business are not correlated with the real needs of the organization. In this case, stronger cultures can cause people to act in ways that are more destructive than promoters, undermining the organization's competitive capacity.

Organizations that benefit from strong organizational cultures get superior performance to other competitors. The major cause of this phenomenon would be that these cultures tend to align, direct and energize members of the organization towards specific goals. However, this is only to the extent that these goals are important goals of the firm, set out in strategies and policies both at global level and partly on functions and on other considerations.

Thus, whether we are talking about a public institution, a state or private capital company, a foundation, etc., we can definitely appreciate that a healthy organizational culture is a safe chance for success it is one of the main factors that can determine the performance of that organization. 


\section{References}

1. M. Năstase, Cultura organizatională și managerială, București (2004)

2. M. Alvesson, Understanding Organizational Culture, (Sage, London, 11, 2002)

3. W. G. Ouchi, Z. Theory, How American Busines Can Meet the Japanese Challenge, (Addison Wesley, Reading, Mass., 41, 1981)

4. T. Peters, R. H. Waterman, In Search of Excellence: Lessons from America's Best Run Companies, (Harper \& Row, New York, 103, 1982)

5. A. Laurent, International Studies of Management and Organization, 10 (1980)

6. O. Nicolescu, I. Verboncu, Fundamentele Managementului Organizatiei, (Ed. Tribuna Economică, București, 273, 2001)

7. E. Schein, Organizational Culture and Leadership, (Jossey-Bass Publishers, San Francisco, 12, 1992)

8. G. Hofstede, Cultures and Organizations, (Harper Collins Business, London, 1994)

9. ***,https://www.slideshare.net/liliahitu/2-cultura-organizationala (accesed on 15.03.2019)

10. Gh. Gh. Ionescu, A. Toma, Cultura organizațională și managementul tranziției, (2001)

11. O. Nicolescu, I. Verboncu, Fundamentele managementului organizaţiei, (Ed. Tribuna Economică, Bucureşti, 2002)

12. ***,https://www.researchgate.net/publication/266014672_STATUTUL_SI_ROLUL_MANAGE RULUI (accesed on 15.03.2019)

13. J. P. Kotter, J. L. Heskett, Cultură şi performanță corporativă.(Presă gratuită, New York, 1992)

14. E. Edelhauser, Tendințe ale utilizării metodelor avansate în managementul organizaţiilor româneşti, Craiova, http://cis01.central.ucv.ro/upload/lucrari_dr/487_rez-en.pdf, (2011). 